\title{
Emergency rescue: the perspective and practicability of applying E-Cell electric engineering vehicles
}

\author{
Jie Jiang ${ }^{1, *}$, Gang $\mathrm{Wu}^{1}$, Wenzhe $\mathrm{Chen}^{2}$, Zehao Wang ${ }^{1}$, and Yanan Jiao ${ }^{3}$ \\ ${ }^{1}$ Haidian Power Supply, State Grid Beijing Electric Power Company, Beijing, China \\ ${ }^{2}$ Electric Power Dispatching Center, Central China Branch of State Grid Corporation of China, Wuhan, China \\ ${ }^{3}$ Customer Service Center, State Grid Beijing Electric Power Company, Beijing, China
}

\begin{abstract}
Copying with the increasingly severe energy crisis and air pollution, new energy vehicles will be an inexorable trend in the near future. The E-Cell electric engineering vehicles will replace conventional oil-fired ones gradually. This paper analyses the current situation and tendency of EVs in brief, explains the function of E-Cell electric engineering vehicles and its roles in maintaining grid stability, peak load shifting and 24-hour emergency rescue service for EVs. Concerning technical application, this paper primarily designs vehicle intelligent terminal systems, Battery Management System(BMS), cable charging, wireless charging and self-charging systems. Finally, this paper designs the billing modes of charging process, and accounts for billing process of vehicle intelligent terminal systems by flow chart to ensure the accuracy during charging process.
\end{abstract}

\section{Introduction}

The fuel of conventional vehicles is mainly based on gasoline and diesel, consuming a mass of non-renewable resources every year, and exhaust emission will bring air pollution. Under the pressure of limited resources and environment, various countries take corresponding measures. Developed countries or districts such as California State, Netherlands, Norway, Germany, France, and British publish the lock-up time of petrol vehicles successively. Guobin Xin, the undersecretary of Ministry of Industry and Information, comes up with the schedule of ceasing conventional petrol vehicles. EVs will play a more crucial part in reducing the consumption of non-renewable resources and abating environmental contamination[1]. It will be an inevitable trend that EVs substitute conventional petrol vehicles.

\section{Prospects and current situation}

With the research and development of rechargeable batteries with large capacity, the cost of rechargeable batteries reduces continually and driving mileage of EVs increases sharply. Since Tesla Roadster launched in 2008, Tesla Inc set off a wave of EVs globally. By the end of 2017, EV sales around the world has hit 1,090,000 with year-on-year growth of more than 56.2 precent, and EV sales in China have hit 448,820 with year-on-year growth of more than 70.9 percent[2]. Nevertheless, the number of charging piles cannot satisfy the rapid development of EVs. By the end of September 2018, EV holdings have reached 2,319,000 while the number of public charging piles is approximately $168,000[3]$. Consequently, the number of public charging piles and the flexibility of battery charging have tremendously restricted the development of EVs. With the dramatic soar in the number of EVs, EV failure rate increases and timely emergency rescue appears to be of essence.

\section{Functions implemented}

\subsection{4-hour emergency rescue for EVs}

E-Cell electric engineering vehicles possess the fundamental functions that conventional ones are equipped with, including maintenance to the power distribution networks, overhead lines and cable lines. Additionally, E-Cell electric engineering vehicles could provide 24-hour emergency rescue for EVs, including malfunction auto-testing system, quick charging service, etc. Malfunction auto-testing system could realize smart identification to fault types and send fault messages to the maintenance center. It will automatically activate smart on-board terminal system and provide quick charging service if the system detects EV energy depletion. As is shown in fig.1, customers could dial service hotline and apply for malfunction service by mobile APP when EVs break down or energy drains out. While customer service center order receiving, the center will pinpoint customer location and match defective vehicles with nearest E-Cell electric engineering vehicles to provide EV emergency rescue.

*Corresponding author: jiangjie1001@126.com 


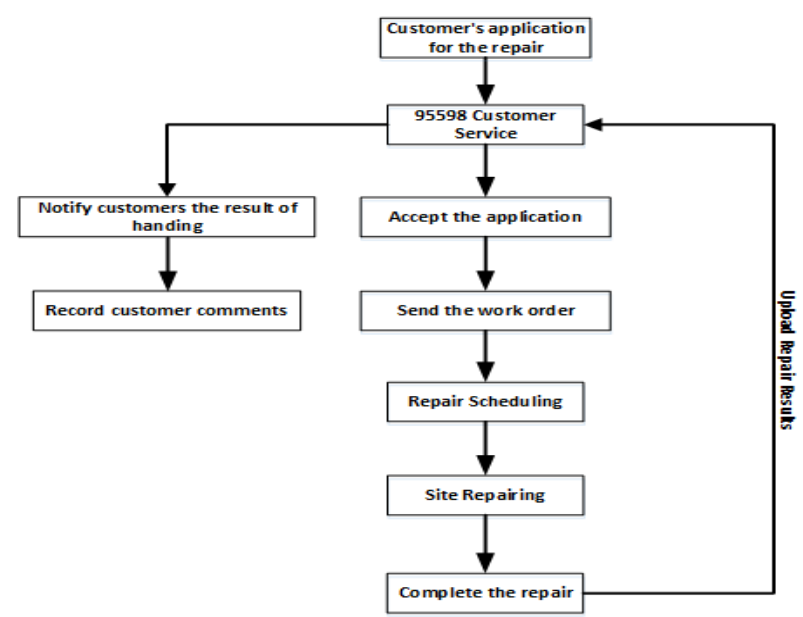

Fig. 1. The flow chart of 95598 Customer Service.

\subsection{Peak load shifting}

E-Cell electric engineering vehicles could save much electric energy once, and energy saving system could realize the peak load shifting to the power grid on the principle of "Valley Charging, Peak Discharge". E-Cell electric engineering vehicles could charge at night when demand is low, and pump power back to the grid during peak energy periods. Peak load shifting is in favor of balancing power system, reducing losses of power distribution network, and maintaining the stability of the power grid. At present, many domestic cities execute peak-valley price. Consequently, peak load shifting contributes to saving charging expenses and improving economic performance.

For Beijing, since June 15th, 2016, Beijing Electric Power Corporation has been performed peak and valley time price for public charging piles. The peak time price is approximately twice the price of the valley time, which is shown in Table 1. In consequence, making the most of off-peak electric energy will minimize E-Cell electric engineering operating costs.

Table 1. The charging standards of peak-vally price in Beijing.

\begin{tabular}{|c|c|c|c|}
\hline $\begin{array}{c}\text { Time } \\
\text { Selection }\end{array}$ & $\begin{array}{c}\text { Price of } \\
\text { Electricity } \\
(\mathbf{R M B} / \mathbf{k W h})\end{array}$ & $\begin{array}{c}\text { Service } \\
\text { Charge } \\
(\mathbf{R M B} / \mathbf{k W h})\end{array}$ & $\begin{array}{c}\text { Specific } \\
\text { Time }\end{array}$ \\
\hline Peak Period & 1.0044 & 0.80 & $\begin{array}{c}10: 00 \sim 15: 00 \\
18: 00 \sim 21: 00\end{array}$ \\
\hline $\begin{array}{c}\text { Ordinary } \\
\text { Period }\end{array}$ & 0.6950 & 0.80 & $\begin{array}{c}7: 00 \sim 10: 00 \\
15: 00 \sim 18: 00 \\
21: 00 \sim 23: 00\end{array}$ \\
\hline $\begin{array}{c}\text { Valley } \\
\text { Period }\end{array}$ & 0.3964 & 0.80 & $23: 00 \sim 7: 00$ \\
\hline
\end{tabular}

\section{Intelligent system}

\subsection{Smart on-board terminal system}

As is shown in fig.2, smart on-board terminal system mainly consists of power electronic converter, signal isolation module, digital control module, electric charge computation module, Global Positioning System(GPS) module, auxiliary power source module, etc[4]. Primarily, external power source delivers energy to smart on-board terminal system and realizes energy conversion by power electronic converter. The function of signal isolation module is to isolate strong and weak signal, which prevents strong field interference with communication signals. Digital control module is counted as the neural center of smart on-board terminal system and is responsible for intelligent control of the whole system. The function of auxiliary power source is offering energy to control circuit, and ensuring the stabilization and high-efficiency of control circuit. The function of electric charge computation module is to guarantee the accuracy of computational process. GPS module realizes accurate positioning to repairing EVs and real-time contact with headquarters.

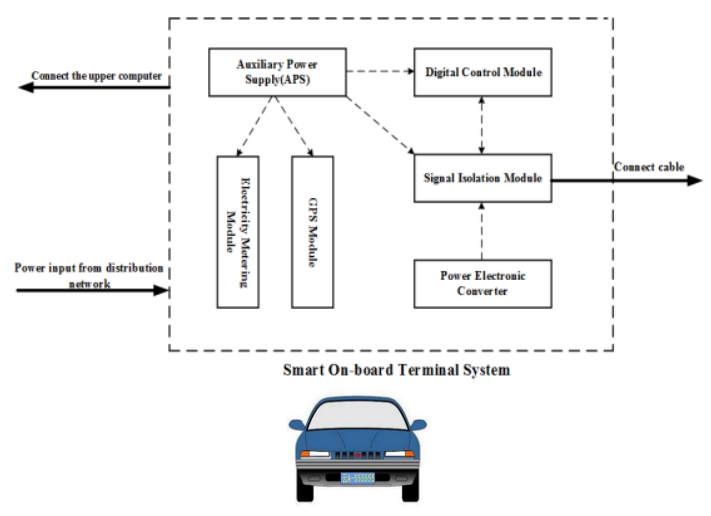

Fig. 2. Smart On-board Terminal System.

\subsection{Battery Management System (BMS)}

Considering the volume and weight capacity, E-Cell electric engineering vehicles could carry Li-ion batteries with capacity of approximate $150 \sim 300 \mathrm{kWh}$. Allowing for carrying large quantities of Li-ion batteries, the security of battery system naturally attracts tremendous attention. Serving as the vital link between EVs and power batteries, BMS is deemed as the kernel of EV automatic systems and the functions of it are battery parameter detection, charging and discharging control, battery fault diagnosis, balancing control, thermal management, etc. As is shown in fig.3, battery parameter detection mainly consists of the battery cell temperature detection, battery total voltage and current detection[5]. On the basis of battery status, charge and discharge control guarantees the security of charge-discharge process, preventing overvoltage and overcurrent. The functions of fault diagnosis are releasing early warnings and judging fault types by diagnosis algorithm. On account of performance imbalance and differences, certain battery cells might appear overheated and balancing control is needed to ensure each battery cell working in balance. The function of thermal management is checking cell temperature, working at preference 
temperature, and extending battery life by adopting appropriate cooling methods.

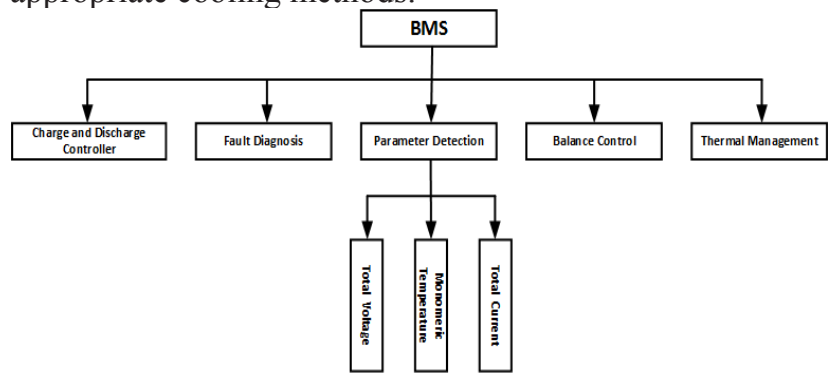

Fig. 3. The chart of Battery Management System.

\subsection{Motor Control Unit (MCU)}

Serving as the core electronic control unit, MCU system is composed of coolant system, power electronic unit, control circuits, underlying software, control algorithm software, which is shown in fig. 4.

While the E-Cell electric engineering vehicles are running, MCU system is capable of controlling the motor under specified torque and revolving speed. During the process, DC electric power is converted into high voltage alternating current and actuates the motor outputting mechanical energy. The hardware circuit of MCU adopts modularizing and platform-based design philosophy. The power drive circuit employs multiple fault diagnosis protection design and the part of power circuit uses IGBT modular parallel control technology.

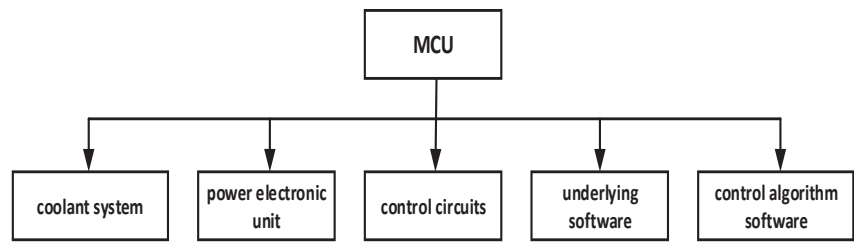

Fig. 4. The chart of Motor Control Unit.

\section{Discussions about applied technology}

\subsection{Quick charging technology}

In the past, the critical factor restricting EV development is long charging time. With the sustainded in-depth study of quick charging technology, it resolves the EV development bottleneck effectually. Wired Charging Technology could be divided into constant voltage mode, constant current mode and pulse charging mode.

When adopting constant voltage mode, the charging time is short whereas it might bring about over-charging to EVs during the early stage of charging and cannot guarantee batteries fully charged. When adopting constant current mode, batteries can be deeply charged whereas the charging time is long.

As to the defects of constant voltage mode and constant current mode, the pulse charging technology has gained extensive attention for the past few years. When adopting pulse charging technology, the charging rate is fast and battery life spans could be extented by effective methods. The disadvantages of pulse charging technology are high equipment cost and high installation requirements. Literature six puts forward a kind of pulse frequency current control technique. When the state of charge(SOC) raises from $20 \%$ to $80 \%$, it takes approximately 16 minutes, and the temperature rise is less than $4^{\circ} \mathrm{C}[6]$. As shown in fig.5, compared with constant voltage mode, pulse frequency charge is much quicker and the charging time could be less than 20 minutes. Literature seven proposes using Digital Signal Process(DSP) to realize pulse charging, and reducing the output current ripple by high switching frequency[7]. Literature eight comes up with using flyback topology with power factor correction(PFC) to actualize the bi-directional flow of the energy and high power factor[8].

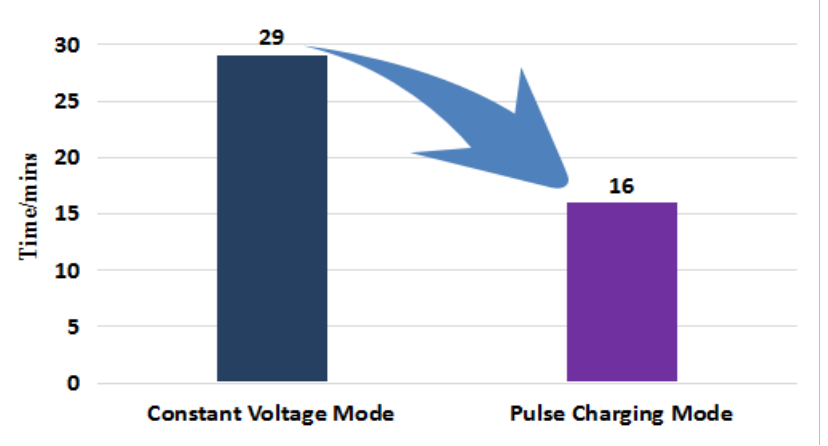

Fig. 5. The comparison of charging time.

\subsection{Wireless charging technology}

As for the wired charging technology mentioned above, the charging piles take up lots of space and are vulnerable to human destruction. In recent years, wireless charging technology is turned to be the focus of research. If using wireless charging technology, it provides many advantages, including flexibility, extensibility, implementation security, and less space demand. Nevertheless, the weaknesses of wireless charging technology are low transmission efficiency and high facility cost. On the basis of charging principles, it can be devided into electromagnetic induction wireless charging and magnetic resonance wireless charging. As is shown in fig.6, it depicts the principle of wireless charging technology.

The principle of electromagnetic induction wireless charging is using eletromagnetic coupling to realize power transmission. It is easy to implement while this method can just realize one-to-one charging and the charging distance is short.

The principle of magnetic resonance wireless charging is making transmitting coils and receving coils on the same resonant frequency to realize power transmisson. It can realize one-to-many charging and the charging distance is relatively further while the cost is much higher. Literature nine puts forward using high frequency wide band gap switches to convert more energy in a shorter period of time[9 10]. 


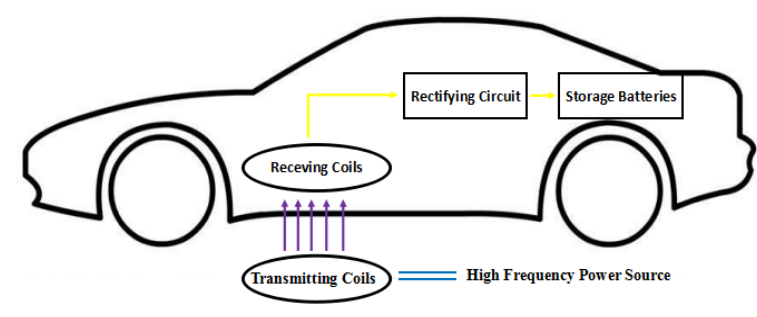

Fig. 6. The principle of magnetic resonance wireless charging.

\subsection{Self-charging system}

If E-Cell electric engineering vehicles depart for somewhere remote, energy depletion is likely to occur. When this happens, intelligent navigation system on-board will locate the nearest charging piles automatically. Moreover, every E-Cell electric engineering vehicle carries a portable charging pile which can connect $220 \mathrm{~V}$ AC. Consequently, in case of no charging piles nearby, the portable charging pile can be used to convert $\mathrm{AC}$ power into $\mathrm{DC}$ power, providing energy for E-Cell electric engineering vehicles.

\section{The design of billing system on-board}

When EVs use up its energy and cannot be started, customers could use specific mobile APP or call State Grid 24-hour hotline "95598" for rescue. E-Cell electric engineering vehicles will arrive at the customers' location within the shortest time as soon as they receive rescue instrcutions. The flow block of billing system on-board is depicted in fig.7.

First of all, the EV charger connects the customer's $\mathrm{EV}$ and the intelligent terminal on-board will identify whether it connects successfully or not. If it fails, the phonetic system will prompt an error and customers should try it all over again. If succeed, it will turn to verify emergency personnel's identity. As a result of emergency power supply, the system just provides quick charging service and customers could pay the bill according to time or electric quantity. When it starts, the intelligent terminal on-board will monitor the charging state and upload charging data to distribution command center in real time. After the batteries are fully charged, the system will print the bill automatically for customers.

\section{Conclusions}

With the expansion of EV scales, the quantity of roadside assistance will inevitably soar. Under the guidance of service theory "Your power, Our care", State Grid Corporation of China will serve each customer heart and soul. For the E-Cell electric engineering vehicles proposed in this paper, they will deliver high quality, high efficiency and highly specialized service for every rescue request. With the insistent innovation of charging technology, BMS and smart terminal, the E-Cell electric engineering vehicles will emerge upon the scenes and benefit each customer in the coming future.

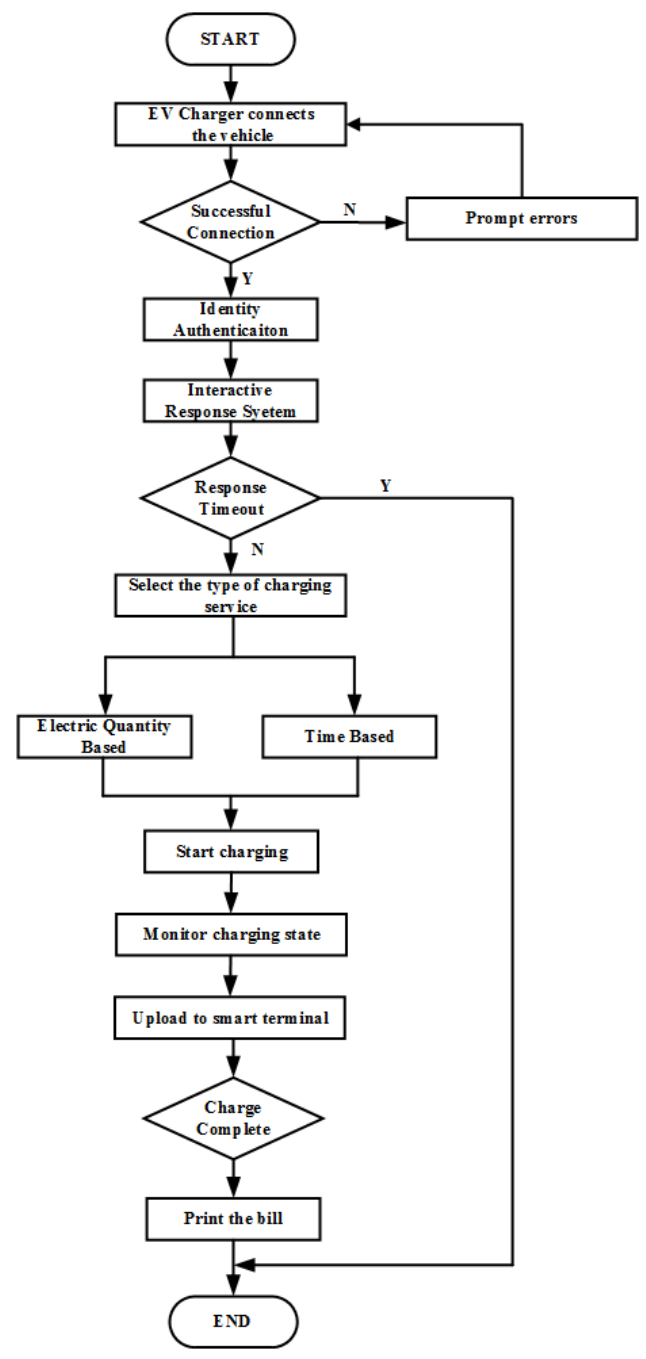

Fig. 7. The flow chart of billing system.

\section{References}

1. Jonatan J. Gomez Vilchez, Patrick Jochem, Wolf Fichtner. EV market development pathways - An application of System Dynamics for policy simulation[C]. 2013 World Electric Vehicle Symposium and Exhibition (EVS27), 2013:1-9.

2. Ofweek New Energy Vehicles [EB/OL]. http://nev.ofweek.com/2018-04/ART-71011-8420-30 220061.html, 2018-04-10.

3. Market Research Report on Global New Energy Vehicles[EB/OL]. http://www.askci.com/news/chany e/20180807/1010581127965.shtml, 2018-10-19

4. Xiaoxuan $\mathrm{Hu}$, Kun Wang, Xiulong Liu, et al. Energy Management for EV Charging in Software-Defined Green Vehicle-to-Grid Network[J]. IEEE Journals \& Magazines, 2018, 56(5):156-163.

5. George Hilton, Mahdi Kiaee, Thomas Bryden, et al. A Stochastic Method for Prediction of the Power Demand at High Rate EV Chargers[J]. IEEE Transactions on Transportation Electrification, 2018:1-1.

6. Phoompat Jampeethong, Surin Khomfoi. An EV Quick Charging Station Using a Pulse Frequency 
Current Control Technique[C]. 12th International Conference on Electrical Engineering/Electronics, Computer, Telecommunications and Information Technology (ECTI-CON), 2015:1-5.

7. Chih-Chiang Hua, Ching-Hsiang Hsu. Implementation of a Regenerative Pulse and Equalization Battery Charger Using a DSP[C]. IEEE Power Electronics and Drive Systems, 2005: 955-959.

8. K. C. Tseng, T. J. Liang, J. E Chen, and M. T. Chang. High Frequency Positive/Negative Pulse Charger with Power Factor Correction[C]. IEEE Power Electronics Specialists Conference, 2002: 671-675.

9. Efficient Wireless Power Charging of Electric Vehicle by Modifying the Magnetic Characteristics of the Transmitting Medium[J]. IEEE Transactions on Magnetics, Volume: 53, Issue: 6, June 2017.

10. Lei Zhao, Duleepa J. Thrimawithana, Udaya Kumara Madawala, et al. A Misalignment Tolerant Series-hybrid Wireless EV Charging System with Integrated Magnetics[J]. IEEE Early Access Articles, 2018:1-1. 